\title{
A mulher no Facebook: uma análise a partir do Sexismo Ambivalente
}

Women on Facebook: an analysis based on Ambivalent Sexism

Mujeres en Facebook: un análisis basado en el Sexismo Ambivalente

DOI: https://doi.org/10.1590/1809-5844202116

Natalia Fernandes Teixeira Alves ${ }^{1}$

https://orcid.org/0000-0002-0722-1485

Luana Elayne Cunha de Souza ${ }^{1}$

https://orcid.org/0000-0001-9425-9598

Luciana Maria Maia ${ }^{1}$

https://orcid.org/0000-0003-1491-5685

Rafaelly Naira da Silva ${ }^{1}$

https://orcid.org/0000-0003-0130-1852

Ágatha Aila Amábili de Meneses Gomes ${ }^{1}$

https://orcid.org/0000-0002-7143-9876

${ }^{1}$ (Universidade de Fortaleza, Centro de Ciências da Saúde, Programa de Pós-Graduação em Psicologia. Fortaleza - CE, Brasil).

\section{Resumo}

O sexismo, compreendido como atitudes negativas contra as mulheres, pode ser manifestado sob uma forma hostil ou benevolente. A partir disso, realizou-se uma pesquisa qualitativa, do tipo exploratória, de caráter documental, que teve como objetivo analisar conteúdos sexistas em páginas do Facebook dirigidas ao público masculino. Fez-se uma análise de conteúdo das postagens selecionadas tendo como referência a Teoria do Sexismo Ambivalente. Os resultados indicaram que o sexismo hostil ainda é fortemente compartilhado, evidenciado por postagens que tentam controlar o comportamento, depreciar a capacidade e objetificar o corpo da mulher. Expressões do sexismo benevolente também foram identificadas, com a especificidade de que são formas facilmente propagadas devido ao caráter aparentemente positivo, velado por um discurso de cuidado, proteção 
e humor. Tais resultados mostram que o sexismo mantém-se e segue difícil de ser combatido, uma vez que não é facilmente percebido pela sociedade.

Palavras-chave: Facebook. Mulher. Estereótipo de gênero. Sexismo. Violência.

\begin{abstract}
Sexism, understood as negative attitudes toward women, can be manifested in a hostile or benevolent way. From this, a qualitative research of the exploratory type of documentary character was carried out, that had as objective to identify and to analyze sexist contents on Facebook pages targeted at the male audience. A content analysis was done from the Ambivalent Sexism Theory of the selected posts. The results indicated that hostile sexism is still heavily shared, evidenced by posts that attempt to control behavior, demean capacity, and objectify the woman's body. Expressions of benevolent sexism have also been identified, with the specificity that they are easily propagated forms due to the seemingly positive character, veiled by a discourse of care, protection and humor. Such results show that sexism remains and remains difficult to combat, since it is not easily perceived by society.
\end{abstract}

Keywords: Facebook. Woman. Gender stereotype. Sexism. Violence.

\title{
Resumén
}

El sexismo, comprendido como actitudes negativas contra las mujeres, puede manifestarse bajo una forma hostil o benevolente. A partir de eso, se realizó una investigación cualitativa del tipo exploratorio de carácter documental, que tuvo como objetivo identificar y analisar contenidos sexistas en páginas de Facebook dirigidas al público masculino. Se hizo un análisis de contenido a partir de la Teoría del Sexismo Ambivalente de las publicaciones seleccionadas. Los resultados indicaron que el sexismo hostil todavía es fuertemente compartido, evidenciado por posturas que intentan controlar el comportamiento, depreciar la capacidad y objetivar el cuerpo de la mujer. Las expresiones del sexismo benevolente también fueron identificadas, con la especificidad de que son formas fácilmente propagadas debido al carácter aparentemente positivo, velado por un discurso de cuidado, protección y humor. Tales resultados muestran que el sexismo se mantiene y sigue siendo difícil de combatir, ya que no es fácilmente perceptible por la sociedad.

Palabras clave: Facebook. Mujer. Estereotipo de género. Sexismo. Violencia.

\section{Introdução}

No cenário atual, conquistas foram alcançadas no que concerne à diminuição das desigualdades sociais e de gênero, principalmente por meio de lutas, lideradas majoritariamente por mulheres. Essas lutas caracterizam os movimentos feministas, que tentam diariamente romper com barreiras sociais historicamente impostas pelo patriarcado (SANTOS et al., 2016). Ao analisar tais sociedades, como a brasileira, percebe-se que as relações sociais se estabeleceram e se desenvolveram ao longo dos anos em função de uma diferenciação de sexo, baseada em características corporais, e entre o dualismo de 
gênero, masculino e feminino (MUNIZ, 2017). Nesse contexto, relações não horizontais subsidiaram a noção de superioridade dos homens em detrimento da valorização das mulheres (SILVA, 2010).

Apesar disso, as mulheres têm ocupado espaços que historicamente eram destinados apenas aos homens, principalmente quando se trata da esfera da vida pública (SANTOS et al., 2016). Tem-se, assim, a conquista de direitos, como o direto de votar, de ocupar cargos políticos e de exercer diferentes funções no mercado de trabalho, inclusive em profissões que por muito tempo foram consideradas exclusivamente masculinas, como mecânico de automóvel e motorista. Entretanto, não se pode desconsiderar que as condições de homens e mulheres nesses espaços ainda são desiguais (PRONI; PRONI, 2018).

No mercado de trabalho, por exemplo, os homens ocupam a maioria dos cargos de chefia, enquanto, as mulheres estão em maior proporção naqueles relacionados ao cuidado e à organização (PRONI; PRONI, 2018). Essas são caraterísticas ligadas à população feminina, devido ao papel atribuído socialmente às mulheres de manter a ordem do lar e a boa criação dos filhos (SILVA, 2010). Ressalta-se que essa realidade ainda é notória em contextos onde é crescente o número de mulheres com o currículo superior ou equiparado ao dos homens (PRONI; LEONE, 2013).

É possível observar também reverberações dessa desigualdade social e de gênero no índice de violência sofrida pelas mulheres. Essa violência muitas vezes só é percebida ou reconhecida quando há agressão física, entretanto, pode ser ainda psicológica, patrimonial, sexual e moral (MUNIZ, 2017). Vale ressaltar que, comumente, essas violências ocorrem de forma simultânea, como no caso do ciclo da violência doméstica, em que a agressão física normalmente vem precedida de outros tipos de violência, já praticadas e naturalizadas (CARVALHO; OLIVEIRA, 2016).

No Brasil, no ano de 2018, dentre as 4.519 mulheres que foram assassinadas, 30,4\% foram concernentes à prática de feminicídio, o que representa um crescimento de 6,6\% em relação a 2017. Isso indica que uma mulher foi assassinada no país a cada duas horas (ATLAS DA VIOLÊNCIA, 2020). Em relação aos registros de estupro e estupro de vulnerável dos anos de 2017 e 2018, as mulheres constituíam 81,8\% das vítimas (ANUÁRIO BRASILEIRO DE SEGURANÇA PÚBLICA, 2019).

Compreendendo que esses fenômenos perpassam por questões estruturais da sociedade, faz-se necessário um entendimento dessas desigualdades à luz das teorias de preconceito, uma vez que o preconceito consiste em uma atitude hostil dirigida a uma pessoa que pertence a um grupo, apenas por ela pertencer àquele grupo (ALLPORT, 1954). Enquanto atitude, o preconceito é dividido em três componentes. Um componente cognitivo, que corresponde aos estereótipos, isto é, o que se pensa de um grupo a partir de características atribuídas a ele; um afetivo, que diz respeito aos sentimentos em relação a esse grupo; e um comportamental, que corresponde à intenção de agir frente a esse grupo (LIMA, 2013, RODRIGUES; ASSAMAR; JABLONSKI, 2009). Ressalta-se que o preconceito não é recente 
e pode ser encontrado em quase todas as culturas do mundo, contribuindo para cercear os direitos e a dignidade humana de membros de diversos grupos desvalorizados socialmente, como é o caso da população feminina (SILVA, 2010).

Nesse sentido, a violência contra a mulher pode ser compreendida como uma expressão de preconceito, o qual, quando direcionada à mulher, é denominado sexismo, com itinerários que estão para além da ordem da violência corporal e/ou psicológica. Essa envolve também práticas cotidianas, expressas em discursos enraizados no imaginário social, por mitos, crenças e ideologias, os quais dão subsídios para os elevados índices de feminicídios. A violência contra as mulheres está velada no mascaramento e na subordinação da linguagem cotidiana, no uso de expressões e de diversos jogos de linguagem e nas palavras de duplo sentido (SILVA, 2014).

\section{Sexismo como forma de violência}

O sexismo é caracterizado por atitudes negativas inflexíveis contra as mulheres (COSTA et al., 2015) e pode ser observado no discurso, advindo de uma construção cultural que perpetua a assimetria de gênero, sendo esse um instrumento que permeia não só a fala de homens, mas também de mulheres. Esses discursos advindos da própria mulher são intrínsecos às sociedades patriarcais, nas quais a população feminina é ensinada e estimulada a agir conforme estereótipos de gênero, bem como normas e valores sexistas, permitindo que esse sistema se sustente e até se fortaleça (SILVA, 2010).

Com mudanças significativas nas normas sociais e na legislação de diversos países sobre a violência contra a mulher, observou-se um declínio nas formas de preconceito e de discriminação flagrante e explícita (CAMINO et al., 2001). Essas mudanças resultaram em um aumento de novas formas de expressão do preconceito, caracterizadas por serem mais sutis e veladas, sendo, consequentemente, mais difíceis de serem percebidas. É relevante salientar que essas formas de expressões são influenciadas e até mesmo definidas pelas normas sociais salientes no contexto no qual ocorrem (MCDONALD; CRANDALL, 2015).

Nessa perspectiva, tem-se a Teoria do Sexismo Ambivalente (TSA), que descreve como funciona este fenômeno a partir de duas dimensões do sexismo: o hostil e o benevolente (GLICK; FISKE, 1996). Por sexismo hostil, entende-se a forma mais flagrante de preconceito contra a mulher, aproximando-se do conceito clássico de preconceito apresentado por Allport (1954). Já o sexismo benevolente, consiste em atitudes interrelacionadas ao cuidado, evidenciando e descrevendo a mulher como frágil (FERREIRA, 2004, FORMIGA; GOUVEIA; SANTOS, 2002, GLICK; FISKE, 1996).

Ainda segundo a TSA, essas duas dimensões são compostas por três elementos denominados: paternalismo, diferenciação de gênero e heterossexualidade, que se expressam de forma diferente em cada uma delas. No sexismo hostil, essas características adquirem um sentido mais agressivo. Desse modo, o paternalismo qualifica-se por ser dominante e 
busca controlar a mulher; a diferenciação de gênero assume uma conotação competitiva, objetivando, por meio de crenças depreciativas, colocar o homem em uma posição superior; e a heterossexualidade assume uma manifestação hostil, em que há um tendência dos homens de ver as mulheres apenas como objetos sexuais (BARRETO; ELLEMERES, 2005, GLICK; FISKE, 1996, KILIANSKI; RUDMAN, 1998).

Para o sexismo benevolente, esses elementos assumem tons aparentemente positivos. Nesse caso, o paternalismo passa a ser protetor, com base no entendimento de que as mulheres devem ser cuidadas e providas pelos homens; a diferenciação de gênero perpassa pela compreensão de que essas devem complementar os homens; e a heterossexualidade manifesta-se nas relações afetivo-sexuais íntimas, em que a mulher deve satisfazer as necessidades românticas dos homens (BARRETO; ELLEMERES, 2005, GLICK; FISKE, 1996, KILIANSKI; RUDMAN, 1998). Ressalta-se que embora a TSA enfatize especificamente as relações entre homens e mulheres, essas questões também podem ser percebidas nas relações não heterossexuais.

Embora a sociedade brasileira seja atualmente orientada por valores e normas sociais igualitárias, o que fez com que houvesse um aumento das expressões de sexismo benevolente, as expressões de sexismo flagrante ainda são bastante presentes, o que pode ser evidenciado nos alarmantes dados estatísticos de violência contra a mulher. Em relação à manifestação benevolente de preconceito contra a mulher, esse pode se manifestar de forma aparentemente positiva (BENOKRAITIS; FEAGIN, 1995, SWIM et al., 1995), por meio de piadas (GREENWOOD; ISBELL, 2002) ou como uma forma de carinho, delicadeza e proteção (BECKER; WRIGHT, 2011, PADAVIC; RESKIN, 2002).

Nota-se, assim, que as formas de expressão do sexismo embora ainda assumam formatos tradicionais, também apresentam novas configurações menos flagrantes, as quais podem ser evidenciadas em diferentes espaços, como as redes sociais digitais.

\section{Redes sociais digitais e a mulher no Facebook}

Segundo Vermelho et al. (2014), redes sociais digitais correspondem à macroestrutura tecnológica que integra um conjunto de atores sociais, pessoas ou instituições, os quais são conectados por laços sociais e troca de conteúdo. Tais conteúdos podem ser expressos por uma diversidade de formatos, como textuais, sonoros, imagéticos e audiovisuais. Aqui adotou-se como rede social digital de análise o Facebook.

Ainda de acordo com Vermelho et al. (2014, p. 188), "estas ferramentas potencializam a manutenção e a expansão dos laços sociais, além de ajudarem a visualizar as redes de relacionamento das quais cada sujeito faz parte”. Isso possibilita o diálogo, a interação e o compartilhamento de opiniões diversas, uma vez que quaisquer pessoas podem ser produtoras e propagadoras de conteúdo. No entanto, essa possibilidade de múltiplos emissores pode ir além do caráter informativo e contribuir para a difusão de discursos preconceituosos e ofensivos, como os discursos sexistas (SILVA; BRAGA, 2016). 
Para se pensar sobre isso, é importante, inicialmente, problematizar o processo de produção dessas tecnologias, considerando quem cria esses algoritmos e escreve esses códigos (SILVA, 2019). Segundo Noble (2018), o preenchimento automático de uma palavra no espaço de busca, na realidade, é perpassado por relações sociais de poder. Isso porque os algoritmos, em sua maioria, são programados por homens com um perfil que interfere na disposição e classificação do que é ofertado. Uma consequência disso é a dificuldade do algoritmo em interpretar como ofensivos alguns posicionamentos e enunciados, como piadas ou figuras de linguagem.

Nesse sentido, ao se pensar nos conteúdos publicados em redes sociais digitais, como páginas do Facebook, é preciso considerar o fato de que os algoritmos identificam léxicos e discursos similares, indicando ou sugerindo amizades, grupos e conteúdo, de modo a formar uma espécie de "bolha” digital. Isso contribui para o agrupamento de perfis de pessoas com valores semelhantes e que consomem conteúdos similares, o que pode contribuir para a propagação e legitimação do sexismo durante as interações sociais nessas redes.

Uma outra característica que colabora para essa realidade é a possibilidade do anonimato. A dificuldade do propagador de conteúdo em ser identificado, devido o distanciamento físico, pode levar a uma divulgação de informações anônimas, como a criação de perfis falsos, o que pode contribuir para a emissão de discursos preconceituosos. Somado a isso, ainda há possibilidade do compartilhamento de conteúdo de forma ampla e rápida, podendo a propagação dessas ideias atingir muitas pessoas em pouco tempo (SILVA; BRAGA, 2016).

Silva et al. (2011) explanam que tais discursos ofensivos nas redes sociais digitais são compostos por dois elementos básicos, a discriminação e a externalidade, e tendem a insultar, intimidar ou assediar pessoas devido a alguma característica específica, como cor, sexo ou orientação sexual. Ainda segundo os autores, esse conteúdo traz efeitos nocivos para o público-alvo, como a violação de direitos fundamentais e o ataque à dignidade humana. Além disso, podem incitar ou convocar outras pessoas a participar desses discursos, ampliando sua dimensão e fomentando possíveis ações diretas, o que se torna ainda mais nocivo com o grande poder difusor da Internet.

Em relação especificamente ao preconceito sofrido pela mulher nesses espaços, há uma espécie de continuação da construção da imagem feminina que já vem sendo compartilhada pela mídia, sobretudo nos anúncios publicitários. Determinadas propagandas representam a mulher como um objeto de consumo e desejo, em que estas se encontram em uma posição erotizada, inferior e submissa aos homens. Esse mesmo padrão de imagem da mulher pode ser observado em páginas no Facebook, que tratam da mulher em uma perspectiva estereotipada ou depreciativa. Nesses locais, observam-se compartilhamentos de conteúdo sexista, que inferiorizam e banalizam a violência a que essa mulher é submetida na vida real (TORRECILHA, 2016).

Nesse sentido, a ascensão da Internet possibilitou uma maior rapidez e disseminação de informações, mas também contribuiu para o compartilhamento de ideias estereotipadas e 
preconceituosas em relação à mulher. Isso ainda é mais evidente quando se pensa no perfil dos criadores e programadores dos algoritmos do Facebook, que, por sua vez, podem refletir ideias sexistas, como dito anteriormente. Com base no que foi explanado, o presente estudo teve como objetivo geral analisar conteúdos sexistas em páginas do Facebook dirigidas ao público masculino.

\section{Método}

\section{Tipo de Pesquisa}

Trata-se de uma pesquisa qualitativa, do tipo exploratória, de caráter documental. É qualitativa por ocupar-se com um nível de realidade que não pode ser quantificado, trabalhando com o universo dos significados, motivos, crenças, valores e atitudes. Nesse sentido, os fenômenos devem ser compreendidos e interpretados levando-se em conta aspectos culturais e históricos que permeiam as relações humanas (MINAYO, 2015). É exploratória por proporcionar maior familiaridade com a problemática, de modo a torná-la mais explícita ou a possibilitar a proposição de hipóteses (GIL, 2016). Por fim, caracteriza-se como documental por buscar identificar, organizar e avaliar as informações contidas em um documento, além da contextualização dos fatos em determinados momentos (MOREIRA, 2005). No presente trabalho, os documentos utilizados foram as páginas do Facebook, por serem de livre acesso e caráter público.

\section{Amostra}

Compõem a amostra dessa pesquisa o conteúdo de 48 imagens postadas em sete páginas do Facebook dirigidas ao público masculino, sendo estas: "Homem de Caráter”, “Papo de Homem”, “Homem Tradicional”, “Homem Homem”, “Macho em Série”, “Sujeito Homem” e "Homem de Verdade”. No momento da coleta, entre outubro a dezembro de 2018, essas variavam entre $30 \mathrm{mil}$ a dois milhões de seguidores e possuíam postagens semanais ou mensais de forma aleatória, tendo todas, pelo menos, 300 imagens com frases contendo algum conteúdo referente ao objetivo da página.

\section{Procedimentos de Coleta}

Para definição das páginas do Facebook com as postagens que seriam analisadas, estabeleceu-se como critérios de seleção páginas disponíveis a partir do descritor “homem”, na aba de busca de páginas do Facebook. Como critérios de exclusão, foram eliminadas as páginas que continham menos de 15 mil seguidores, tendo em vista que, comparativamente, teriam menos acessos e visibilidade. Em seguida, realizou-se uma leitura preliminar de postagens das páginas pré-selecionadas. Nesse momento, foram excluídas páginas que não 
contemplavam postagens relacionadas ao objetivo da pesquisa, apresentando conteúdos exclusivamente motivacionais, religiosos ou sobre videogames e desenhos animados. Feito isso, alcançou-se um número final de sete páginas.

O processo de coleta ocorreu entre os meses de outubro a dezembro de 2018, utilizando-se computadores e celulares, por meio do acompanhamento das postagens que eram feitas diariamente ou semanalmente nessas páginas. Para seleção das postagens, utilizou-se o critério de saturação, ou seja, interrompia-se a coleta quando o conteúdo das postagens ficava repetitivo, de modo que não acrescentava informações novas à pesquisa (BALDIN; MUNHOZ, 2011).

A fim de minimizar o viés no processo de seleção do conteúdo, a coleta foi feita por duas pesquisadoras separadamente, as quais selecionavam aquelas imagens que eram identificadas com conteúdo sexista, com base na Teoria do Sexismo Ambivalente, e as arquivavam em bancos de dados separados e individuais, os quais possuíam respectivamente 56 e 52 imagens. Feito isso, realizaram uma checagem simultânea das postagens arquivadas e entraram em um consenso daquelas que seriam analisadas, totalizando 48 imagens postadas. Ressalta-se que as publicações analisadas foram postadas entre os anos 2016 e 2018.

\section{Análise dos dados}

Os dados foram analisados mediante a Análise de Conteúdo Temática (BARDIN, 2011), seguindo um conjunto de procedimentos sintetizados nas seguintes etapas: leitura preliminar do material selecionado; definição de categorias a partir do conteúdo analisado; descrição e discussão das categorias à luz da Teoria do Sexismo Ambivalente (GLICK; FISKE, 1996). Os materiais encontrados foram divididos em duas categorias temáticas, sexismo hostil e sexismo benevolente. Essas foram ainda subdivididas de acordo com os elementos constituintes de cada uma dessas dimensões, isto é, paternalismo, diferenciação de gênero e heterossexualidade. É importante ressaltar que nenhum nome ou perfil de pessoas que seguem essas páginas foram expostos no corpo do trabalho.

\section{Resultados e Discussão}

Pelo caráter pessoal e de pouca censura, característico das redes sociais digitais, é possível a exteriorização de opiniões preconceituosas (MUNIZ, 2017, SILVA; BRAGA, 2016). Diante disso e do objetivo da presente pesquisa, ao analisar o conteúdo de imagens postadas em páginas do Facebook dirigidas ao público masculino, verificaram-se postagens sexistas, tanto de caráter hostil quanto benevolente, segundo a Teoria do Sexismo Ambivalente.

Voltando-se primeiramente à dimensão hostil, em relação ao primeiro elemento paternalismo dominante, verificaram-se conteúdos baseados na ideia de que os homens devem controlar o comportamento feminino (LEE; FISKE; GLIKE, 2010). Exemplos desse paternalismo são postagens como: “ninguém é estuprada em casa lavando louça”, 
o que remete à ideia de obediência e restrição ao espaço privado como elementos de uma suposta segurança e proteção contra o estupro, cuja culpa é, nessa perspectiva, imputada à mulher. Contudo, dados estatísticos demostram uma realidade distinta, em que, segundo o Ministério da Saúde (2018), 71,2\% das violências sexuais contra crianças e 58,2\% contra adolescentes, ambos do gênero feminino, ocorreram dentro de casa e foram cometidas por homens de seu convívio.

Além disso, essa postagem também remete e retroalimenta a divisão sexual do trabalho, em que se nota uma tentativa de controle do que a mulher deve fazer, caracterizado pela imposição de um lugar e de um papel que essa deve ocupar. Esse papel baseia-se nos padrões tradicionais de gênero e ocupações tidas como típicas femininas, vinculadas ao cuidado do lar. Acerca disso, Biroli (2016) destaca que a divisão sexual do trabalho, por meio de atribuições desiguais de responsabilidades aos homens e mulheres, está na base do sistema patriarcal, onde as mulheres têm sua força de trabalho explorada e os homens beneficiam-se coletivamente desse sistema. Isso também pode ser visto em outras postagens, à exemplo: "sábado de spa: spa da louça, spa lavar, spa passar, spa limpar".

$\mathrm{O}$ segundo elemento da dimensão hostil diz respeito à diferenciação de gênero e configura-se no fenômeno em que o homem desenvolve atitudes competitivas em relação à mulher, por meio de crenças depreciativas sobre ela, a fim de aumentar sua própria confiança e autoestima. Nesse sentido, os homens acreditam que, em sua condição de superioridade, devem dominar posições sociais relacionados a poder e decisão, demonstrando aversão e intolerância quando mulheres conseguem ocupar esses espaços (GLICK; FISKE, 1996, FERREIRA, 2004). Essa postura pode ser identificada em postagens, sobretudo, relacionadas à ex-presidenta Dilma Rousseff, que demonstram uma realidade ainda presente, que é a negação de espaços de poder às mulheres (LIMA; ANTONINO, 2016). Como exemplo, temse uma postagem contendo a foto de Dilma com a frase "é óbvio que o impeachment é exagero, bastava um psicotécnico”, que além de depreciar as competências femininas na execução de um cargo de poder e liderança, como a presidência, ainda faz uma associação ao estereótipo feminino da mulher "louca”. Outro exemplo refere-se a uma postagem contendo uma foto de um homem simulando bater na bunda da ex-presidenta, seguida da frase "para cada curtida, uma chibatada”, que diminui e vulgariza o corpo feminino. Tais exemplos indicam a tentativa de limitar a presença das mulheres em espaços de dominância, como a política, e ratificar uma divisão sexista do trabalho.

Seguindo nessa perspectiva, a outra forma de expressão hostil percebida é a heterossexualidade hostil, na qual os homens têm o desejo de dominar as mulheres, não demonstram vulnerabilidade nas relações íntimas e percebem essas mulheres apenas como objetos sexuais (GLICK; FISKE, 1996, FERREIRA, 2004). Tal objetificação sexual descreve que as mulheres são tratadas como objetos a serem vistos e tocados, e não como seres humanos inteligentes. Esse processo acontece quando o corpo, ou partes desse corpo, são acentuados e desassociados da mulher como pessoa e à mesma é atribuído o papel de dar prazer ao homem (FREDRICKSON; ROBERTS, 1997, SZYMANSKI; MOFFITT; CARR, 
2011). Aqui, tem-se como exemplo postagens com as seguintes frases: "O homem que fala que o lugar da mulher é na cozinha é porque não sabe o que fazer com ela no quarto"; "Às vezes tudo que uma mulher precisa é de uma língua quente e habilidosa"; "8 maravilha do mundo: bunda da mulher”; "Existem coisas que não precisam ser ensinadas” referindo-se a um pequeno garoto olhando fixamente o decote de uma mulher; "Mulher é um negócio tão bom que homem gosta de mulher, mulher está pegando mulher e tem homem querendo ser mulher". Tais postagens demonstram uma subordinação da mulher ao homem, em que é vista como um objeto que está a serviço do prazer masculino. Ou seja, há uma manutenção de uma posição passiva das mulheres, de objeto sexual, de subserviência aos imperativos masculinos, dentro de uma sociedade machista (TORRECILHA, 2016).

Expressões do sexismo benevolente também foram identificadas. Ao que se refere ao caráter paternalista, nota-se uma imagem da mulher como um ser frágil, necessitada de atenção e cuidado por parte do homem. Esse paternalismo benevolente remete à relação do homem como pai, sendo esse uma figura de autoridade, devendo prover e proteger a mulher, que se apresenta como indefesa e incapaz (FERREIRA, 2004). Nas páginas analisadas, evidencia-se esse fenômeno em postagens como: "Ensine a ela que você é protetor e o comandante dela. Seja Homem!”; “As mulheres devem ser valiosas e cuidadosas e protegidas pelos homens"; "Tão delicada assim não pode fazer essas coisas de homem”; "Beijo na testa significa muito mais que beijo na boca, significa respeito, carinho e proteção”. Esses exemplos, historicamente, têm simbolizado comportamentos de cavalheirismo, trazendo consigo uma interdependência altamente romantizada das relações sociais desiguais estabelecidas entre os gêneros (GLICK; FISKE, 2011).

Os outros elementos que compõem a dimensão benevolente, isto é, a diferenciação de gênero e a heterossexualidade, também puderam ser encontrados nas postagens analisadas. Nessa perspectiva, o papel social da mulher seria o de complementar e satisfazer as necessidades românticas masculinas (FERREIRA, 2004, FORMIGA; GOUVEIA; SANTOS, 2002, GLICK; FISKE, 1996). A esse respeito, tem-se como exemplo postagens com as frases: "O sonho de todo homem é ter uma mulher de honra e caráter e deixar um legado para seus filhos"; e "Nada contra as que se vestem com pequenos shorts ou blusas, mas se for para namorar, homens preferem as de vestidos mais longos". Nota-se uma ênfase na submissão da mulher em relação ao homem, onde essa deve se comportar adequadamente, para satisfazer as necessidades românticas masculinas do que seria uma namorada/esposa/mãe ideal. Esses comportamentos relacionam-se à idealização do lugar da mulher na relação heterossexual, em que parece haver um silenciamento de suas próprias vontades e necessidades em detrimento daquelas dos homens. Além disso, percebe-se o estabelecimento da vestimenta da mulher considerada respeitável, associada a valores e normas sociais de gênero.

Dessa forma, as postagens mostram a crença de que as mulheres possuem características positivas que servem para complementar a posição social dos homens (ROJAS, 2010). Isso porque, segundo Weeks (2010), os padrões de sexualidade feminina são um produto do poder 
dos homens e servem para definir o que é necessário e desejável por e para eles. Isso, por sua vez, coloca a mulher em uma posição de submissão e dependência da vontade do homem.

Além disso, encontrou-se também manifestações benevolentes nas postagens disfarçadas de um teor cômico. Isso se deu na compreensão de que o teor cômico das postagens, aqui referidas, que faz rir e não possui a intenção de ofender, na verdade surge como forma de diminuir e neutralizar a seriedade do conteúdo exposto, disfarçando-se de piadas, ou seja, apresentando-se como algo aparentemente positivo. Desse modo, entende-se que a utilização do humor como forma de disseminação do preconceito pode ser interpretada como um mecanismo de legitimação do sexismo nesses espaços digitais. Isso faz com que o escárnio de mulheres seja encarado de forma engraçada, que, por sua vez, cria uma norma social tolerante ao sexismo benevolente, que ajuda a mantê-lo e propagá-lo (FORD; WENTZEL; LORION, 2001).

A partir disso, destacam-se alguns exemplos de postagens sexistas expostas como forma de piadas, que reforçam estereótipos femininos, mas vão além, colocando a figura da mulher em um lugar de menor valor e status na estrutura social. Exemplo disso, tem-se as piadas às mulheres loiras associando-as a uma capacidade intelectual inferior, tais como: "Duas mulheres loiras estavam andando pela rua quando uma diz: - Olha um Passarinho morto! A outra olha para o céu e diz: - Aonde?”. Outro exemplo seria: “Qual a diferença entre a loira e a escova de dente? É que seus amigos não usam a escova de dente”, que além dessa inferiorização intelectual, ainda reforça a mulher enquanto objeto para a satisfação do desejo masculino. Ressalta-se ainda que a frase se refere a um perfil específico de mulher, que atende a um padrão de beleza socialmente imposto, de modo que dentro do imaginário masculino a mulher loira, branca e magra é traduzida como um troféu para uso sexual (BARROS, 2019).

Ainda quanto ao sentido cômico das postagens, viu-se também conteúdos se referindo à mulher dona de casa, como por exemplo: "Por que as mulheres casam de branco? Para combinar com a geladeira, o fogão e a lava louça"; e àquelas que não sabem dirigir: "Ele: querida o que está fazendo? Ela: nada, amor. Coisas de mulher. Ele: bateste com o carro outra vez?” e “Dia 8 de Março, dia internacional da mulher”, esta última frase representada com uma imagem com vários carros batidos. Esses exemplos reforçam estereótipos femininos que, de modo sutil, buscam manter o status quo, isto é, a norma social vigente, em que os papéis sociais se encontram divididos a partir do gênero. Observa-se que as piadas funcionam como uma tentativa de atacar mulheres que desviam do papel imposto socialmente, de modo a determinar espaços e afazeres que essa pode assumir, supondo-se que ela deva estar satisfeita ao se restringir a esses espaços.

Nesse contexto, percebe-se que a utilização do humor facilita a disseminação e atenua o preconceito, o que contribui para que grupos socialmente desfavorecidos, como as mulheres, continuem sendo humilhados, assediados e oprimidos de forma aceitável (FORD; WENTZEL; LORION, 2001). Segundo Silva (2014), nessa forma humorística de expressão 
de sexismo, a vítima é agredida sem nenhum pudor, uma vez que tudo pode ser dito, já que o preconceito se dá por meio de uma apresentação lúdica, que traz consigo um tom de não criticidade. Ressalta-se, portanto, que piadas sexistas podem desempenhar muitos papéis, como, por exemplo, influenciar a objetificação sexual das mulheres, a desvalorização de suas habilidades pessoais e profissionais e o apoio à violência contra as mulheres (BEMILLER; SCHNEIDER, 2010, SOUSA; FIGUEIRA, 2017).

Sendo assim, compreende-se que o Sexismo Ambivalente se apresenta de diferentes formas e contribui para a manutenção e tolerância de diferentes tipos de violência contra a mulher, além de servir de base para atitudes e comportamentos que relativizam, legitimam e naturalizam esse fenômeno. Desse modo, Swim e Hyers (2009) afirmam que compreender as crenças sexistas hostis é importante para entender a tolerância de uma pessoa em julgar diferentes situações que violentam uma mulher, principalmente quando essa se encontra em uma posição de poder. Em contraste, a compreensão do sexismo benevolente ajuda a perceber reações acerca dessa situação de violência, que pode se dá através da neutralidade, silenciamento ou humor.

Estudos sobre sexismo indicam que essas duas dimensões do Sexismo Ambivalente são prejudiciais às mulheres, pois visam manter o status quo das relações de gênero (GLICK; FISKE, 1996, 2001). Embora o sexismo hostil traga uma forma mais agressiva de expressão desse preconceito, o sexismo benevolente, mesmo apresentando-se aparentemente positivo, também traz prejuízos e consequências negativas, o que torna essas expressões de sexismo complementares e equivalentes entre si (GLICK; FISKE, 2011).

Ademais, sem desconsiderar os índices alarmantes de violência e sexismo hostil em relação a mulher, é importante destacar que o sexismo benevolente pelo seu conteúdo disfarçado de cuidado, proteção e humor, pode ser perpetuado e aceito de forma mais fácil, sendo muitas vezes reproduzido pelas próprias mulheres. Para Souza (2016), é necessário problematizar os pensamentos e as intenções por trás do sexismo benevolente para que seja possível garantir às mulheres a liberdade delas serem quem elas desejam ser e, consequentemente, evitando que elas vivenciem, devido aos estereótipos de gênero, um destino fixo e imutável.

Com base no que foi exposto, percebe-se que a análise a partir do sexismo ambivalente ajuda a compreender diversas formas e experiências de preconceito e de discriminação que a mulher sofre no seu dia a dia, seja propagada a partir da violência propriamente dita, da objetificação sexual, da atribuição de espaços e papéis que essa mulher deve ocupar socialmente ou através do humor.

\section{Considerações Finais}

No presente trabalho pôde-se observar que, apesar das redes sociais digitais, como o Facebook, representarem avanços nas formas humanas de se relacionar e se comunicar, as mesmas podem também ser ferramentas de propagação de mensagens que fazem apologia 
a diferentes tipos de violência contra a mulher. Nesse sentido, as redes sociais digitais podem contribuir para manter representações negativas desse grupo, que sustentam crenças, estereótipos e ideologias, bem como antipatias e aversões, as quais perpetuam graves desigualdades de gênero.

Embora pesquisas mostrem que o sexismo hostil tem diminuído por conta da maior disseminação de leis e normas sociais que visam a proteção da mulher, além dos avanços e direitos conquistados pelas mulheres, notou-se no presente trabalho que conteúdos hostis ainda são bastante compartilhados e aceitos. Tais conteúdos estavam relacionados sobretudo à tentativa de controle do comportamento feminino, depreciação de suas capacidades e objetificação de seus corpos. Isso levanta reflexões sobre o papel legitimador do Facebook acerca de conteúdos mais hostis, tendo em vista a possibilidade do anonimato e distanciamento do emissor, podendo torná-lo um instrumento de negação do politicamente correto e do que seria esperado em uma sociedade igualitária.

Em relação às postagens de conteúdo benevolente, ressalta-se que esta forma de sexismo é dificilmente percebida pela sociedade por seu viés aparentemente positivo, seja por meio de cuidado, proteção, humor e valorização de um ideal de mulher. É importante ressaltar que essas manifestações sexistas não se configuram como um novo discurso, mas, sim, caracterizam-se como uma alternativa a mais, uma opção extra de autorizar o preconceito contra a mulher na contemporaneidade.

Deste modo, percebe-se que o sexismo segue difícil de ser enfrentado, uma vez que ele é facilmente disseminado nas redes sociais digitais, como o Facebook. Tal cenário dificulta a mudança de visão em relação à imagem da mulher, apesar de já haver movimentos de resistência e pesquisas que se propõem dar subsídios ao combate de diferentes práticas de violência contra grupos minoritários. Ressalta-se ainda que essa desigualdade de gênero enquanto um fenômeno global, configura-se nas vivências díspares do acesso aos direitos e do exercício do poder, mas também na aversão e inferiorização a tudo aquilo que se assemelhe às tradicionais ideias do que é ser mulher (BIROLI, 2016).

Assim, confia-se que o presente trabalho traz uma contribuição tanto para a análise de um fenômeno contemporâneo e existente em boa parte das sociedades ocidentais, como é o comportamento dos indivíduos no campo digital, quanto para a análise de um fenômeno histórico e de extrema relevância social, como é o caso da desigualdade de gênero e suas inúmeras consequências. Pesquisas em redes sociais digitais são importantes, visto que esse é um espaço que possibilita expressões livremente e trata-se de um dos principais meios de comunicação atuais. Porém, é importante que novos estudos sob essa perspectiva sejam realizados para perceber como se dá a manifestação de comportamento sexista em outros contextos sociais para além da internet.

\section{Referências}

ALLPORT, G. The nature of prejudice. Cambridge: Addison-wesley, 1954. 
BALDIN, N; MUNHOZ, E. M. B. Educação ambiental comunitária: uma experiência com a técnica de pesquisa snowball (bola de neve). REMEA - Revista Eletrônica do Mestrado em Educação Ambiental, v. 27, 2011.

BARDIN, L. Análise de conteúdo. São Paulo: Edições 70, 2011.

BARRETO, M.; ELLEMERS, N. The burden of benevolent sexism: How it contributes to the maintenance of gender inequalities. European Journal of Social Psychology, v. 35, n. 5, p. 633-642, 2005.

BARROS, A. P. O. Discursos sobre a sexualidade e o corpo da mulher nas HQs: reproduções e desconstruções. Brazilian Journal of Development, v. 5, n. 10, p. 21094-21111, 2019.

BEMILLER, M. L.; SCHNEIDER, R. Z. It's not just a joke. Sociological Spectrum, v. 30, n. 4, p. 459479, 2010.

BECKER, J. C.; WRIGHT, S. C. Yet another dark side of chivalry: Benevolent sexism undermines and hostile sexism motivates collective action for social change. Journal of Personality and Social Psychology, v. 101, n. 1, p. 62, 2011.

BENOKRAITIS, N. V.; FEAGIN, J. R. Modern sexism: Blatant, subtle, and covert discrimination. Pearson College Div, 1995.

BIROLI, F. Autonomia, dominação e opressão. In: MIGUEL, L. F., BIROLI, F. O feminismo e a política: uma introdução. São Paulo: Boi Tempo, 2a. ed., 2016.

BIROLI, F. Divisão Sexual do Trabalho e Democracia. Dados, Rio de Janeiro, v. 59, n. 3, p. 719-754, 2016. CAMINO, L. et al. A face oculta do racismo no Brasil: uma análise psicossociológica. Revista de Psicologia Política, v. 1, n. 1, p. 13-36, 2001.

CARVAlHO, J. R; OLIVEIRA, V. H. de. Pesquisa de Condições Socioeconômicas e Violência Doméstica e Familiar Contra a Mulher. Instituto Maria da Penha, 2016.

COSTA, P. A. et al. Adaptação dos inventários de sexismo moderno para Portugal: o inventário de sexismo ambivalente e o inventário de ambivalência em relação aos homens. Psicologia: Reflexão e crítica, v. 28, n. 1, 2015.

FERREIRA, M. C. Sexismo hostil e benevolente: inter-relações e diferenças de gênero. Temas em Psicologia, SBP, v. 12, n. 2, p. 119-126, 2004.

FORD, T. E.; WENTZEL, E. R.; LORION, J. Effects of exposure to sexist humor on perceptions of normative tolerance of sexism. European Journal of Social Psychology, v. 31, n. 6, p. 677-691, 2001.

FORMIGA, N. S.; GOUVEIA, V. V.; SANTOS, M. N. dos. Inventário de sexismo ambivalente: sua adaptação e relação com o gênero. Psicologia em Estudo, Maringá, v. 7, n. 1, p. 103-111, 2002.

FÓRUM BRASILEIRO DE SEGURANÇA PÚBLICA. 11 Anuário Brasileiro de Segurança Pública, 2017. Disponível em: http://www.forumseguranca.org.br/estatisticas/tableau-dignidade/talebadeestupro. Acesso em: 18 nov. 2018.

FREDRICKSON, B. L.; ROBERTS, T. Teoria da objetificação: para compreender as experiências vividas pelas mulheres e os riscos para a saúde mental. Psicologia das mulheres, v. 21, n. 2, p. 173-206, 1997.

GIL, A. C. Métodos e técnicas de pesquisa social. 6. ed. São Paulo: Atias, 2016.

GLICK, P.; FISKE, S. T. The ambivalent sexism inventory: differentiating hostile and benevolent sexism. Journal of Personality and Social Psychology, v. 70, n. 3, p. 491-512, 1996.

GLICK, P. et al. Beyond prejudice as simple antipathy: hostile and benevolent sexism across cultures. Journal of Personality and Social Psychology, v. 79, n. 5, p. 763, 2000.

144 Intercom - RBCC

São Paulo, v. 44, n. 1, p.131-147, jan./abr. 2021 
GLICK, P; FISKE, S. T. An ambivalent alliance: Hostile and benevolent sexism as complementary justifications for gender inequality. American Psychologist, v. 56, n. 2, p. 109, 2001.

GLICK, P.; FISKE, S. T. Ambivalent sexism revisited. Psychology of Women, v. 35, n. 3, p. 530-535, 2011. GREENWOOD, D.; ISBELL, L. M. Ambivalent sexism and the dumb blonde: Men's and women's reactions to sexist jokes. Psychology of Women Quarterly, v. 26, n. 4, p. 341-350, 2002.

INSTITUTO DE PESQUISA ECONÔMICA APLICADA - IPEA. Atlas da violência de 2018, 2018. Disponível em: https://www.ipea.gov.br/portal/images/stories/-PDFs/relatorio_institucional/180604_atlas_ da_violencia_2018.pdf. Acesso em: 28. jun. 2020.

KILIANSKI, S. E.; RUDMAN, L. A. Wanting it both ways: do women approve of benevolent sexism?. Sex Roles, v. 39, n. 5-6, p. 333-352, 1998.

LEE, T. L.; FISKE, S. T.; GLICK, P. Next gen ambivalent sexism: Converging correlates, causality in context, and converse causality, an introduction to the special issue. Sex Roles, v. 62, n. 7-8, p. 395-404, 2010.

LIMA, E. C. A.; ANTONINO, R. M. "Leviandades” eleitorais: a abertura das cortinas para um espetáculo misógino. Revista de Ciências Sociais - Política \& Trabalho, v. 1, n. 44, 2016.

LIMA, M. E. O. Preconceito. In: CAMINO, L.; TORRES, A. R.; LIMA, M. E. O.; PEREIRA, M. E. (Orgs.). Psicologia social: temas e teorias. Brasília: Technopolitik, p. 589-640, 2013.

MCDONALD, R. I.; CRANDALL, C. S. Social norms and social influence. Current Opinion in Behavioral Sciences, v. 3, n. 147-151, 2015.

MINAYO, M. C. Pesquisa social: teoria, método e criatividade. Editora Vozes Limitada, 2015.

BRASIL. Ministério da Saúde. Análise epidemiológica da violência sexual contra crianças e adolescentes no Brasil, 2011 a 2017, v. 49, 2018.

MOREIRA, S. V. Análise documental como método e como técnica. In: DUARTE, J.; BARROS, A. (Org.). Métodos e técnicas de pesquisa em comunicação. São Paulo: Atlas, 2005. p. 269-279.

MUNIZ, D. C. G. As feridas abertas da violência contra mulher no Brasil: estupro, assassinato e feminicídio. In: STEVENS, C. et al. (Orgs). Mulheres e Violências: Interseccionalidades. Brasília: Technopolitik, 2017. p. 36-49.

NOBLE, S. U. Algorithms of oppression: How search engines reinforce racism. NYU Press, 2018.

PADAVIC, I.; RESKIN, B. F. Women and men at work. Pine Forge Press, 2002.

PRONI, M. W.; LEONE, E. T. Desigualdades de gênero e raça no mercado de trabalho brasileiro. Regulação do trabalho e instituições públicas. São Paulo: Editora Fundação Perseu Abramo, v. 2, 2013.

PRONI, T. T. R. W.; PRONI; M. W. Discriminação de gênero em grandes empresas no Brasil. Estudos Feministas, v. 26, n. 1, p. 1-21, 2018.

ROJAS, J. M. R. Sexismo ambivalente, paternalismo masculino e ideología política en adultos jóvenes de la ciudad de Lima. Pensamiento Psicológico, v. 7, n. 14, 2010.

RODRIGUES, A.; ASSMAR, E. M. L.; JABLONSKI, B. Cognição Social. In: RODRIGUES, A.; ASSMAR, E. M. L.; JABLONSKI, B. (Orgs.). Psicologia Social. Petrópolis: Vozes, 2009, p. 67-96.

SANTOS, L. C. et al. Gênero, feminismo e psicologia social no Brasil: análise da revista Psicologia \& Sociedade (1996-2010). Psicologia \& Sociedade, v. 28, n. 3, p. 589-603, 2016.

SILVA, F. K. M. da. Piadas machistas $\mathbf{x}$ piadas feministas: um espaço de disputa entre identidades. 62f. 2014. Monografia (Graduação em Letras) - Universidade Federal da Paraíba. 
SILVA, R. L. et al. Discursos de ódio em redes sociais: jurisprudência brasileira. Revista Direito GV, São Paulo, v. 7, n. 2, p. 445-468, 2011.

SILVA, S. G. Preconceito e discriminação: as bases da violência contra a mulher. Psicologia: ciência e profissão, v. 30, n. 3, p. 556-571, 2010.

SILVA, T. Teoria Racial Crítica e Comunicação Digital: conexões contra a dupla opacidade. In: ANAIS DO $42^{\circ}$ CONGRESSO BRASILEIRO DE CIÊNCIAS DA COMUNICAÇÃO. Sociedade Brasileira de Estudos Interdisciplinares da Comunicação. Belém, Pará. 2019. Anais....

SILVA, T. P.; BRAGA, C. F. Racismo e sexismo sofrido por mulheres negras no facebook. In: XXXIX CONGRESSO BRASILEIRO DE CIÊNCIAS DA COMUNICAÇÃO, São Paulo: [s.n.], 2016. Anais....

SOUSA, B. B; FIGUEIRA, M. D. A Representação da Mulher em Textos Humorísticos: uma análise do gênero piada á luz da pragmática. PERcursos Linguísticos, v. 7, n. 15, p. 92-106, 2017.

SWIM, J. K. et al. Sexism and racism: Old-fashioned and modern prejudices. Journal of Personality and Social Psychology, v. 68, n. 2, p. 199, 1995.

SWIM, J. K. Y HYERS, L. Sexism. In: NELSON, T. D. (Org.) Handbook of prejudice, stereotyping, and discrimination. Nueva York: Psychology Press/Taylor and Francis, p. 407-430, 2009.

SZYMANSKI, D. M.; MOFFITT, L. B.; CARR, E. R. Sexual objectification of women: advances to theory and research. The Counseling Psychologist, v. 39, n. 1, p. 6-38, 2011.

TORRECILHA, J. C. A mídia e as mensagens de gênero, de contornos sexistas, veiculadas por alguns anúncios publicitários. Revista de Audiovisual Sala 206, n. 5, 2016.

VERMELHO, S. C. et al. Refletindo sobre as redes sociais digitais. Educ. Soc., v. 35, n. 126, p. 179-196, 2014.

WEEKS, J. O corpo e a Sexualidade. In: LOURO, G. L. O corpo educado: pedagogias da sexualidade. 3. ed. Belo Horizonte: Autêntica Editora, 2010.

\section{Natalia Fernandes Teixeira Alves}

Doutoranda do Programa de Pós-Graduação em Psicologia pela Universidade de Fortaleza (UNIFOR). Bolsista FUNCAP. Integrante do Laboratório de Estudos sobre Processos de Exclusão Social (LEPES). E-mail: nataliafta_@hotmail.com.

\section{Luana Elayne Cunha de Souza}

Doutora em Psicologia Social pela Universidade Federal da Paraíba. Professora Adjunta da Universidade de Fortaleza (UNIFOR). Coordenadora do Laboratório de Estudos sobre Processos de Exclusão Social (LEPES). E-mail: luana_elayne@hotmail.com.

\section{Luciana Maria Maia}

Doutora em Psicologia Social pela Universidade Federal da Paraíba. Professora Titular da Universidade de Fortaleza (UNIFOR). Coordenadora do Laboratório de Estudos sobre Processos de Exclusão Social (LEPES). E-mail: lumariamaia@hotmail.com. 


\section{Rafaelly Naira da Silva}

Mestranda do Programa de Pós-Graduação em Psicologia pela Universidade de Fortaleza (UNIFOR). Bolsista FUNCAP. Integrante do Laboratório de Estudos sobre Processos de Exclusão Social (LEPES). E-mail: rafaellynaira@hotmail.com.

\section{Ágatha Aila Amábili de Meneses Gomes}

Doutoranda do Programa de Pós-Graduação em Psicologia pela Universidade de Fortaleza (UNIFOR). Bolsista FUNCAP. Integrante do Laboratório de Estudos sobre Processos de Exclusão Social (LEPES). E-mail: agatha.aila@hotmail.com.

Recebido em: 28.03.2019

Aprovado em: 14.09 .2020 